ISSN-2575-7601

Volume 3, Issue 1, 13 pages

\title{
The Unrecognized Patient and Economic Burdens of Post Coronary Artery Bypass Grafting Surgery Morbidities: Could Contemporary Medical Therapy Play a Bigger Role?
}

\author{
Abolfazl Dohaei, M.D. ${ }^{1}$, Wayne L. Miller, M.D., Ph.D. ${ }^{1}$ \\ Department of Cardiovascular Disease, Mayo Clinic, Rochester, Minnesota, United States of America. \\ Dohaei.Abolfazl@mayo.edu
}

\begin{abstract}
Background: The recognition of the impact of new medications and the synergic effect of new drug combinations is absent in studies comparing coronary artery bypass grafting surgery (CABG) with medical therapy. There are limited review data regarding the contribution of morbidities after CABG on outcomes.

Methods: Full texts and data were collected from Mayo Clinic library, PubMed, and Google Scholar sources. We reviewed all pertinent article texts and study designs and identified relevant studies. Because we intended to include all morbidity results, we gathered all systematic reviews relating to specific morbidities and provided a comprehensive explanation of results. Published articles were assessed from 1994 up to the present time considering contemporary studies regarding morbidities.

Results: The impact of morbidities and economic costs after CABG go unrecognized in the decision process to pursue $\mathrm{CABG}$ while the beneficial effects of newer medications on managing ischemia and cardiovascular outcomes are potentially undervalued.

Conclusions: Considering new medications in the light of the deleterious impact of morbidities and costs following CABG should prompt needed studies to evaluate in a more comprehensive manner the impact of coronary surgical revascularization vs. contemporary medical therapy.

Condensed Abstract: The impact of morbidities and costs after CABG is significant. New studies comparing CABG with MT based on advances in contemporary medications relative to the morbidities and costs following CABG are needed.
\end{abstract}

Keywords: Complication; Coronary revascularization; Follow-up studies; Long-term outcome; Medications

\section{AbBreviations}

AF: Atrial Fibrillation

BARI 2D: the Bypass Angioplasty Revascularization Investigation 2 Diabetes

CABG: Coronary Artery Bypass Grafting

CASS: Coronary Artery Surgery Study

DALYs: Disability Adjusted Life Years

MASS II: the second Medical, Angioplasty, or Surgery Study

MT: Medical Therapy

STICH: Surgical Treatment for Ischemic Heart Failure

www.arjonline.org

Page 1 
The Unrecognized Patient and Economic Burdens of Post Coronary Artery Bypass Grafting Surgery Morbidities: Could Contemporary Medical Therapy Play a Bigger Role?

SYNTAX: the SYNergy between percutaneous coronary intervention with TAXus and surgery

US: United States

\section{INTRODUCTION}

Coronary artery bypass grafting (CABG) surgery is one of the most common major surgeries in the world(1-3), with 156,931CABG-only surgeries performed in the United States (US) alone in 2016 (54\% of total cardiac surgeries)(1). The costs of CABG and its morbidities have a large effect on health systems, patients, and families (4-7). Morbidities after CABG are common (40\% to 50\%)(2,3,8-14) and some are very serious $(3,11,12,15$ 19). If we count disability adjusted life years (DALYs) including years of life lost and years lived with disability associated with each morbidity, we encounter a larger burden which has not been considered in previous studies comparing CABG with medical therapy (MT)(20-24). For example, atrial fibrillation (AF) after CABG is associated with 53.6 years of life lost for one thousand patients during twenty years of follow-up (8). Another very important issue is that studies which compared CABG with MT are not contemporary (20-24) and with new medications and synergic effect of modern combination of drugs in ischemic heart disease, heart failure, diabetes mellitus, hypertension, dyslipidemia, and renal failure(25-37), new evaluationsof CABG versus MT are needed. The aims of our review are to highlight the detrimental impact of morbidities after CABG and their associated patient and economic burdens and the necessity of new studies comparing CABG with MT based on new medications and combinations of the drugs. The impact of CABG-related morbidities on patients, their families, and the economic costs to our health care system are consequential.

\section{METHODS}

Data were collected from three online data bases: Mayo Clinic library, PubMed, and Google Scholar. The research terms used were "CABG", "CABG versus MT", "morbidities after CABG", "names of morbidities and complications after CABG in detail", and "new medications and "combination of drugs for each cardiovascular risk factor". The reference lists of the selected articles yielded via electronic database search were completely examined to find potential relevant articles. The research articles were assessed from 1994 up to the present time. Decision about inclusion of the studies was made independently and was based on the rigor of the study design, longer follow-up durations, effect of study limitations, and contemporary studies especially regarding morbidities. Because we intended to include all morbidity results, we gathered all systematic reviews relating to specific morbidities and provided a comprehensive explanation of results. We included all relevant studies which compared CABG with MT and discussed study results. We referenced new medications which have been proven to be effective at decreasing ischemia and improving cardiovascular outcomes in multiple studies and/or large multicenter randomized control trials. The full reports of articles were reviewed and considered for all relevant data including study designs, clinical validity, statistical analysis, primary and secondary outcomes, and followup time periods; and studies with high risk of bias were not included. Randomized controlled trials with high risk of bias as evaluated by the Cochrane Risk of Bias Tool (Higgins and Green, 2011) were excluded(38).

\section{RESULTS}

\section{Mortality}

Many of the studies which compared CABG with MT demonstrated more increases in event free survival in CABG groups (20-24), but in the Surgical Treatment for Ischemic Heart Failure (STICH) trial CABG versus MT did not decrease all-cause mortality in older patients. In the second Medical, Angioplasty, or Surgery Study (MASS II) trial overall mortality rates were similar in CABG group and MT group, and the Bypass Angioplasty Revascularization Investigation 2 Diabetes (BARI 2D) trial did not show significant differences in major cardiovascular events and death between the revascularization group and MT group $(20,21,39)$. 
The Unrecognized Patient and Economic Burdens of Post Coronary Artery Bypass Grafting Surgery Morbidities: Could Contemporary Medical Therapy Play a Bigger Role?

Angina

Previous studies have shown better freedom from angina in CABG group comparing with MT group $(21,23)$. In MASS II trial, the free from angina rates were 64\% in CABG group and 43\% in MT group(21), although a review of three former large trials showed no differences in the Class 3 and 4 angina during the follow-up of patients between MT group and CABG group(23).

Pain

The most common symptom of patients who seek medical care is chronic pain and surgery is the most common cause of this problem (13) with CABG-related sternotomy or thoracotomy pain $(40,41)$. Various prospective studies of cardiac surgery patients demonstrated that the incidence of chronic pain after sternotomy is $17 \%$ to 56\%(42-44); and meta-analyses of prospective studies showed that the incidence of chronic pain after thoracotomy is $57 \%$ at three months and $47 \%$ at six months $(13,45)$. These patients have worse quality of life, reduced physical activity, and sleep disturbances(46,47). A systematic review of 29 studies revealed that preoperative anxiety plays an important role in development of chronic pain after surgery(48).

\section{Depression and Anxiety}

Substantial numbers of cardiac surgery patients are subject to depression (14-47\%) and anxiety (15-52\%) (12,49-51). Significant depressive symptoms documented in one fifth of CABG patients one year after the operation and it was associated with high level of inflammation after CABG (10,52-54). Depressive disorders remarkably increase mortality and morbidities after cardiac surgery(12,49-51,55,56). The morbidities include persistent post-surgical pain, low adherence to medication, poor physical activity, new coronary events, suppression of immune system and progression of malignant tumors, and increased incidence of infection (49-51,55-57). A meta-analysis of 54 prospective cohort studies showed that there is a significant relationship between depression and risk of coronary artery disease, although the results of this study were limited because of heterogeneity of results in primary studies(57). A systematic review of pre-op predictors of depression and anxiety following CABG explained that a history of depression, neuroticism, female gender, and younger age might be risk factors of post-CABG depression(58).

\section{Inflammation}

A significant inflammatory condition commonly occurs after cardiac surgery and it was diagnosed by high detected levels of inflammatory cytokines such as C-reactive protein, interleukin 6, and interleukin 8 $(10,16,52,54,59,60)$. The main factors which cause the inflammation are surgical trauma, cardiopulmonary bypass, and ischemia-reperfusion injury subsequent to ischemic cardioplegicarrest $(10,16,54,59)$. Inflammation after CABG would contribute to myocardial cell apoptosis and contractile dysfunction, AF, cerebral infarction, cognitive impairment, depression, respiratory dysfunction, renal failure, gastrointestinal problems, shoulder disorders, and pericarditis and post-pericardiotomysyndrome.(2,3,10,18,52,53,59,61-67) A systematic review of 63 studies including 27,363 cardiac surgery patients demonstrated that post-op inflammatory response, reflected mostly via an increased white blood cell blood levels, is associated with the risk of developing post-op atrial fibrillation (60). A similar systematic review of 42 studies involving 8398 cardiac surgery patients showed that post-op levels of inflammatory biomarkers encompassing C-reactive protein, interleukin 6, interleukin 8, and interleukin 10 are significantly related to post-op $\mathrm{AF}(10)$.

\section{Atrial Fibrillation}

Post-operative AF is a very common problem after $\mathrm{CABG}$, affecting up to half of the patients after CABG alone and over $60 \%$ of the patients after combined valvular surgery and CABG $(10,59,68)$. It increases short-term mortality and predicts long-term mortality independently (68-70). It is associated with many adverse sequelae 
The Unrecognized Patient and Economic Burdens of Post Coronary Artery Bypass Grafting Surgery Morbidities: Could Contemporary Medical Therapy Play a Bigger Role?

such as stroke, myocardial infarction, and organ failure among others $(6,10,59,70)$ and it prolongs hospital stay two to five days $(6,60)$. A systemic review about assessment of quality of life in AF patients revealed that quality of life is significantly poorer in AF patients compared to general population and coronary artery disease patients(71). Many reasons are suggested as the pathogenesis of the AF such as inflammation, ischemia from cardiopulmonary bypass, and surgical trauma $(6,10,59,60)$.

\section{Infection}

One of twenty patients (5\%) after cardiac surgery experiences a major infection $(72,73)$ and the infection substantially increases mortality and morbidity $(72,74,75)$. Some of the risk factors are blood transfusion (increased risk with more transfusions), open saphenous vein graft approach, using bilateral internal mammary artery grafts, prolonged ventilation, and post-surgery vasopressor support (72-76). Pneumonia is the most common infection after $\mathrm{CABG}$, involving $3 \%$ of patients $(73,74,77)$. Surgical site infection has the incidence of $1 \%$ to $4 \%$ after $C A B G$ and it is related to significant morbidity and cost $(72,75,78)$. A mete-analysis of 15 randomized controlled trials comparing conventional vein harvesting versus minimally invasive vein harvesting in patients undergoing CABG showed that the rate of leg wound infection is $13 \%$ and $3 \%$, respectively(78). Mediastinitis is an uncommon infection (0.4-4\%), but is caries a high rate of mortality (10-47\%)(17). Prophylactic antibiotics are common after CABG and they are a crucial risk factor of Clostridium difficile infection(79). Recent cases of disseminated infection with Mycobacterium chimaera is a new long term challenge after cardiac surgery(80).

\section{Cerebral Infarction}

Post-CABG stroke is a devastating morbidity which associates with high mortality (acute mortality is up to $38 \%)(15,61,81,82$ ). A meta-analysis of 57 reports ( the analysis was done on 80314 patients) including MASS II trial and the SYNergy between percutaneous coronary intervention with TAXus and surgery (SYNTAX) trial demonstrated that the risk of stroke after CABG is significant and there is a persistent risk of accumulative stroke during five years after procedure(83). In MASS II trial the risk of stroke was $8.4 \%$ in CABG group and $6.9 \%$ in MT group at ten years of follow-up; and in SYNTAX trial the risk of stroke was $4.3 \%$ in left main disease group after CABG and 3.7\% in three vessels disease and left main disease groups after CABG at five years of follow-up $(21,84,85)$. Most of perioperative strokes happen 24 hours after the procedure, although those which happen during first 24 hours are much more lethal $(15,82)$. Some of pathogenic factors of postCABG stroke are manipulation of atherosclerotic aortic arch, utilization of cardiopulmonary bypass, systemic inflammatory reaction, and AF $(61,81,82,86)$. A meta-analysis of 11,398 off-pump CABG cases observed that aortic manipulation significantly increase the risk of neurologic complications after the surgery(86). Studies with magnetic resonance imaging showed that brain infarcts are substantially more common than clinically visible strokes (61).

\section{Cognitive Impairment, Delirium, and Dementia}

Cognitive impairment after CABG is common, involving about $50 \%$ of patients at time of discharge and approximately $42 \%$ after five years of surgery $(2,64,87)$ and it has an enormous effect on the patients' life and their families $(2,87,88)$. The most popular explanatory factors are systemic inflammatory reaction, cerebral hypoperfusion, microemboli, general anesthesia, and specific patient characteristics $(2,64)$. Delirium commonly occurs after cardiac surgery (7.6-67\%)(14,89). Lingehall et al. found an association between delirium after cardiac surgery and late dementia within five years of follow-up(89). A prospective study on 326 CABG patients showed that dementia is significantly higher in these patients at 7.5 years of follow-up. This study also showed an association between post-operative cognitive impairment and mortality(90). Crocker and his colleagues did a systematic review on 14,824 cardiac surgery patients to examine long-term (up to 10 years) outcomes 
The Unrecognized Patient and Economic Burdens of Post Coronary Artery Bypass Grafting Surgery Morbidities: Could Contemporary Medical Therapy Play a Bigger Role?

of post-op delirium. They found that post-op delirium is firmly associated with functional decline, decreased cognition, lower health-related quality of life, hospital readmission, and death(14).

\section{Respiratory Problems}

Following CABG, pulmonary complications were described as a major cause of mortality and morbidity $(3,91$ 93). Patients often experience atelectasis and substantial decrease in pulmonary volumes and oxygenation $(3,93,94)$ and almost all the patients have hypoxemia $(91,92,94)$. A systematic review of 18 trials involving 1457 cardiac surgery patients demonstrated that the incidence of at electasis is $15 \%$ to $98 \%$ and the incidence of pneumonia is $0 \%$ to $20 \%$ after cardiac surgery(95). Westerdahl et al. followed their patients for four months and they observed a significant restrictive pulmonary dysfunction remaining up to four months(94). Some of the pulmonary dysfunction mechanisms are general anesthesia, median sternotomy, utilization of cardiopulmonary bypass, topical cooling for protection of myocardium, dissection of internal thoracic artery, lung injury related to blood transfusion, diaphragmatic dysfunction, phrenic nerve injury, and muscle wasting due to inflammation(3,7,92-94). Large diminution in pulmonary function was observed in patients who have more post-operative increment in blood cortisol and C-reactive protein levels (3).

\section{Renal Failure}

Acute renal failure is a common and debilitating morbidity after cardiac surgery which affects $30 \%$ to $50 \%$ of patients $(11,62,65,66,96)$. Even slight increase in serum creatinine level (less than 0.3 milligrams per deciliter or 26 micromoles per liter) was associated with significant increase in long term mortality and chance of end stage renal disease in large population studies $(97,98)$. About $0.6 \%$ to $5 \%$ of patients immediately after cardiac surgery require dialysis $(11,62,98)$. These patients have really elevated mortality rate (approximately $25 \%$ ) and substantial risk of chronic dialysis(98). A cohort study in the US using the Society of Thoracic Surgeons national database observed that $24 \%$ of patients undergoing CABG have moderate renal failure (glomerular filtration rate $=30-60$ milliliter $/$ minutes $/ 1.73$ square meters)(99).Sajja and his colleagues studied 116 CABG patients who had pre-op non-dialysis dependent renal failure (glomerular filtration rate $\leq 60$ milliliter/minutes/1.73 square meter). They showed that the rate of acute renal failure is significantly higher in on-pump CABG versus off-pump CABG (62\% versus 30\%)(96). Likewise, a systematic review of six randomized controlled trials and sixteen observational studies (including 27,806 CABG patients) demonstrated a substantial decrease in post-op acute renal failure with off-pump CABG than conventional CABG(100). Pathogenesis of renal failure after CABG is multifactorial such as platelet activity, inflammation, emboli, hypothermia, non-pulsatile blood flow and renal hypoperfusion during cardiopulmonary bypass, and drugs $(11,62,65,66)$. About half of CABG patients receive red blood cell products $(73,74)$ and it adversely limits the patients access to kidney transplantation if needed in the future(101).

\section{DISCUSSION}

CABG surgery is among the most frequent major surgeries performed in both the US and Europe (1-3). The mean hospital cost of a CABG surgery is $\$ 40,424$ in the US.(4)In addition, costs for morbidities following CABG are high. For example, expenditures related to post-operative AF are one to two billion dollars per year in the US $(6,59)$. Expenditures related to mediastinitis are more than fifty-eight thousand dollars per episode(5).

Many previous studies comparing CABG with medical treatment showed better improvement in event free survival and angina in CABG group than MT group, but these studies have not been updated from the perspective of contemporary medication therapy(20-24). New medications and synergic effect of modern combinations of drugs in ischemic heart disease, heart failure, diabetes mellitus, hypertension, dyslipidemia, and renal failure have shown a better effect on decreasing ischemia, treatment of significant risk factors, cardiovascular 
The Unrecognized Patient and Economic Burdens of Post Coronary Artery Bypass Grafting Surgery Morbidities: Could Contemporary Medical Therapy Play a Bigger Role?

outcomes, and survival (25-37). STICH trial was the last study comparing CABG with MT in 1212 heart failure patients starting in 2002, and therefore patients were not receiving optimal therapy by current standards. Moreover, every patients had reduced ejection fraction $(<35 \%)$, and hence the result is not attributable to all ischemic heart disease patients. The follow-up duration was 9.8 years and we do not know about the mortality beyond that time frame. The follow-up duration in Coronary Artery Surgery Study (CASS) registry was 15 years and it showed increased mortality rate after 8 to 10 years in CABG group and similar survival for medically and surgically managed patients at 15 years $(20,24)$. STICH trail demonstrated that CABG does not decrease all-cause mortality in older patients. In this trail the number of patients was relatively small in the women's group (12\%) and in the group of patients older than 75 years (7\%); therefore, the CABG outcome was not well supported in these groups (20). BARI 2D trail enrolled 2368 diabetic patients with coronary artery disease. This trial began in 2001 and followed the patients for approximately 5 years and demonstrated that the rates of major cardiovascular events and death were not significantly different in revascularization group and MT group(39). MASS II trial of 611 patients who had multi-vessel coronary artery disease was initiated in 1995 with a follow-up duration of about 10 years. In this study event free survival rates were $74.9 \%$ in CABG group and 69\% in MT group, however overall mortality rates were similar in both groups. Freedom-from-angina rates were $64 \%$ in CABG group and $43 \%$ in MT group (21).

The studies which compared CABG with MT did not account for the years of life lost from post-op morbidities $(20-24,39)$ and unfortunately these morbidities are common following CABG $(2,3,8-13)$. Geulayov and colleagues undertook a prospective study on 1125 CABG patients with 11 years of follow-up. They demonstrated that postoperative depression (especially one year after operation) is related to elevated long term mortality and postoperative anxiety is related to increased long term mortality in women (12). Al-Shaar and colleagues studied 7610 CABG patients for prediction of postoperative AF long term mortality. They showed postoperative $\mathrm{AF}$ is related to increased mortality at 18 years and this association was without the confounding effect of other postoperative complications(68). Ryden et al. studied 29330 isolated CABG patients for long term consequences of postoperative acute renal failure and followed the patients for $4.3 \pm 2.4$ years. They showed that even small increase in serum creatinine level is related to significant increased risk of end stage renal disease and it predicts long term mortality(98).

Years of life lost and years lived with disability following the post-op development of morbidities have not been addressed in previous studies comparing CABG with MT. Costs of CABG and the morbidities are very high. The place of contemporary medications is undefined at the present time. In current guidelines(102)which are based on the above citedstudies, CABG is the Class 1 recommendation for many patients with ischemic heart disease, therefore new studies based on contemporary medical therapy and considering the post-CABG morbidities and costs are essential.

\section{STUDY LimitaTions}

We did not discuss infrequent or more minorpost-CABG morbidities such assurgical re-exploration(19), gastrointestinal problems(18), orthopedic (shoulder) disorders(63), and pericarditis(67) but these are also significant patient concerns.

\section{CONCLUSIONS}

Considering newer and contemporary medications, the burden of morbidities, and the substantial costs of CABG and morbidities following CABG strongly suggests that new era studies comparing in a more comprehensive manner to include longer term post-op morbidities CABG with contemporary MT should be a high value clinical research target.

American Research Journal of Cardiovascular Diseases Page 6 
The Unrecognized Patient and Economic Burdens of Post Coronary Artery Bypass Grafting Surgery Morbidities: Could Contemporary Medical Therapy Play a Bigger Role?

\section{REFERENCES}

1. D'Agostino RS, Jacobs JP, Badhwar V et al. The Society of Thoracic Surgeons adult cardiac surgery database: 2018 update on outcomes and quality. The Annals of thoracic surgery 2018;105:15-23.

2. Bhamidipati D, Goldhammer JE, Sperling MR, Torjman MC, McCarey MM, Whellan DJ. Cognitive Outcomes After Coronary Artery Bypass Grafting. Journal of cardiothoracic and vascular anesthesia 2017;31:707-718.

3. Roncada G, Dendale P, Linsen L, Hendrikx M, Hansen D. Reduction in pulmonary function after CABG surgery is related to postoperative inflammation and hypercortisolemia. International journal of clinical and experimental medicine 2015;8:10938-46.

4. Kilic A, Shah AS, Conte JV et al. Understanding variability in hospital-specific costs of coronary artery bypass grafting represents an opportunity for standardizing care and improving resource use. The Journal of thoracic and cardiovascular surgery 2014;147:109-15.

5. Calderwood MS, Kleinman K, Soumerai SB et al. Impact of Medicare's payment policy on mediastinitis following coronary artery bypass graft surgery in US hospitals. Infection control and hospital epidemiology 2014;35:144-51.

6. Greenberg JW, Lancaster TS, Schuessler RB, Melby SJ. Postoperative atrial fibrillation following cardiac surgery: a persistent complication. European journal of cardio-thoracic surgery : official journal of the European Association for Cardio-thoracic Surgery 2017;52:665-672.

7. Garcia-Delgado M, Navarrete-Sanchez I, Colmenero M. Preventing and managing perioperative pulmonary complications following cardiac surgery. Current opinion in anaesthesiology 2014;27:146-52.

8. Freundlich RE, Maile MD, Hajjar MM et al. Years of Life Lost After Complications of Coronary Artery Bypass Operations. The Annals of thoracic surgery 2017;103:1893-1899.

9. Moazzami K, Dolmatova E, Maher J et al. In-Hospital Outcomes and Complications of Coronary Artery Bypass Grafting in the United States Between 2008 and 2012. Journal of cardiothoracic and vascular anesthesia 2017;31:19-25.

10. Weymann A, Popov AF, Sabashnikov A et al. Baseline and postoperative levels of C-reactive protein and interleukins as inflammatory predictors of atrial fibrillation following cardiac surgery: a systematic review and meta-analysis. Kardiol Pol 2018;76:440-451.

11. Kertai MD, Zhou S, Karhausen JA et al. Platelet Counts, Acute Kidney Injury, and Mortality after Coronary Artery Bypass Grafting Surgery. Anesthesiology 2016;124:339-52.

12. Geulayov G, Novikov I, Dankner D, Dankner R. Symptoms of depression and anxiety and 11-year allcause mortality in men and women undergoing coronary artery bypass graft (CABG) surgery. Journal of psychosomatic research 2018;105:106-114.

13. Bayman EO, Parekh KR, Keech J, Selte A, Brennan TJ. A Prospective Study of Chronic Pain after Thoracic Surgery. Anesthesiology 2017;126:938-951.

14. Crocker E, Beggs T, Hassan A et al. Long-term effects of postoperative delirium in patients undergoing cardiac operation: A systematic review. The Annals of thoracic surgery 2016;102:1391-1399.

15. Mehta A, Gleason T, Wechsler L, Winger D, Wang L, Thirumala PD. Perioperative stroke as a predictor of mortality and morbidity in patients undergoing CABG. Journal of clinical neuroscience : official journal of the Neurosurgical Society of Australasia 2017;44:175-179. 
The Unrecognized Patient and Economic Burdens of Post Coronary Artery Bypass Grafting Surgery Morbidities: Could Contemporary Medical Therapy Play a Bigger Role?

16. Brinkman WT, Squiers JJ, Filardo G et al. Perioperative Outcomes, Transfusion Requirements, and Inflammatory Response After Coronary Artery Bypass Grafting With Off-Pump, Mini-Extracorporeal, and On-Pump Circulation Techniques. Journal of investigative medicine : the official publication of the American Federation for Clinical Research 2015;63:916-20.

17. Kieser TM, Rose MS, Aluthman U, Montgomery M, Louie T, Belenkie I. Toward zero: deep sternal wound infection after 1001 consecutive coronary artery bypass procedures using arterial grafts: implications for diabetic patients. The Journal of thoracic and cardiovascular surgery 2014;148:1887-95.

18. Mahdi A, Noureddine A, Younes $\mathrm{M}$ et al. Upper gastrointestinal bleeding after open heart surgery. Journal of Digestive Endoscopy 2014;5:101.

19. Biancari F, Mikkola R, Heikkinen J, Lahtinen J, Airaksinen KJ, Juvonen T. Estimating the risk of complications related to re-exploration for bleeding after adult cardiac surgery: a systematic review and meta-analysis. European journal of cardio-thoracic surgery 2011;41:50-55.

20. Petrie MC, Jhund PS, She L et al. Ten-Year Outcomes After Coronary Artery Bypass Grafting According to Age in Patients With Heart Failure and Left Ventricular Systolic Dysfunction: An Analysis of the Extended Follow-Up of the STICH Trial (Surgical Treatment for Ischemic Heart Failure). Circulation 2016;134:13141324.

21. Hueb W, Lopes N, Gersh BJ et al. Ten-year follow-up survival of the Medicine, Angioplasty, or Surgery Study (MASS II): a randomized controlled clinical trial of 3 therapeutic strategies for multivessel coronary artery disease. Circulation 2010;122:949-57.

22. O'Connor CM, Velazquez EJ, Gardner LH et al. Comparison of coronary artery bypass grafting versus medical therapy on long-term outcome in patients with ischemic cardiomyopathy (a 25-year experience from the Duke Cardiovascular Disease Databank). The American journal of cardiology 2002;90:101-7.

23. Solomon AJ, Gersh BJ. Management of chronic stable angina: medical therapy, percutaneous transluminal coronary angioplasty, and coronary artery bypass graft surgery. Lessons from the randomized trials. Annals of internal medicine 1998;128:216-23.

24. Davis KB, Chaitman B, Ryan T, Bittner V, Kennedy JW. Comparison of 15-year survival for men and women after initial medical or surgical treatment for coronary artery disease: a CASS registry study. Coronary Artery Surgery Study. Journal of the American College of Cardiology 1995;25:1000-9.

25. Sun $\mathrm{H}$, Guo Z, Li L, Wu N, Yan K, Yan X. CONFIRMATIVE PHASE III GLOBAL CLINICAL TRIAL OF A BOTANICAL DRUG IN PATIENTS WITH CHRONIC STABLE ANGINA (CAESA): NEW TREATMENT OPTIONS FOR MYOCARDIAL ISCHEMIA HEART DISEASE. Journal of the American College of Cardiology 2018;71:A36.

26. Wang $S$, Fan $Y$, Feng $X$ et al. Nicorandil alleviates myocardial injury and post-infarction cardiac remodeling by inhibiting Mst1. Biochemical and biophysical research communications 2018;495:292-299.

27. Rayner-Hartley E, Parvand M, Humphries KH, Starovoytov A, Park JE, Sedlak T. Ranolazine for Symptomatic Management of Microvascular Angina. American journal of therapeutics 2018.

28. Fraccarollo D, Galuppo P, Sieweke JT, Napp LC, Grobbecker P, Bauersachs J. Efficacy of mineralocorticoid receptor antagonism in the acute myocardial infarction phase: eplerenone versus spironolactone. ESC heart failure 2015;2:150-158.

29. McMurray JJ, Packer M, Desai AS et al. Angiotensin-neprilysin inhibition versus enalapril in heart failure. New England Journal of Medicine 2014;371:993-1004. 
The Unrecognized Patient and Economic Burdens of Post Coronary Artery Bypass Grafting Surgery Morbidities: Could Contemporary Medical Therapy Play a Bigger Role?

30. Gordin JS, Fonarow GC. New medications for heart failure. Trends in cardiovascular medicine 2016;26:485492.

31. Fitchett D, Zinman B, Wanner C et al. Heart failure outcomes with empagliflozin in patients with type 2 diabetes at high cardiovascular risk: results of the EMPA-REG OUTCOME® trial. European heart journal 2016;37:1526-1534.

32. Marso SP, Daniels GH, Brown-Frandsen K et al. Liraglutide and cardiovascular outcomes in type 2 diabetes. New England Journal of Medicine 2016;375:311-322.

33. Trujillo JM, Wettergreen SA, Nuffer WA, Ellis SL, McDermott MT. Cardiovascular outcomes of new medications for type 2 diabetes. Diabetes technology \& therapeutics 2016;18:749-758.

34. Ruilope LM, Investigators SS. Fixed-Combination Olmesartan/Amlodipine Was Superior to Perindopril+ Amlodipine in Reducing Central Systolic Blood Pressure in Hypertensive Patients With Diabetes. The Journal of Clinical Hypertension 2016;18:528-535.

35. Mourad J-J, Amodeo C, de Champvallins M, Brzozowska-Villatte R, Asmar R. Blood pressure-lowering efficacy and safety of perindopril/indapamide/amlodipine single-pill combination in patients with uncontrolled essential hypertension: a multicenter, randomized, double-blind, controlled trial. Journal of hypertension 2017;35:1481-1495.

36. Sattar N, Preiss D, Robinson JG et al. Lipid-lowering efficacy of the PCSK9 inhibitor evolocumab (AMG 145 ) in patients with type 2 diabetes: a meta-analysis of individual patient data. The Lancet Diabetes \& Endocrinology 2016;4:403-410.

37. Watanabe R, Suzuki J-i, Wakayama K et al. Angiotensin II receptor blocker irbesartan attenuates cardiac dysfunction induced by myocardial infarction in the presence of renal failure. Hypertension Research 2016;39:237.

38. Higgins JP, Altman DG, Gøtzsche PC et al. The Cochrane Collaboration's tool for assessing risk of bias in randomised trials. Bmj 2011;343:d5928.

39. Group BDS. A randomized trial of therapies for type 2 diabetes and coronary artery disease. New England Journal of Medicine 2009;360:2503-2515.

40. Ruel M, Shariff MA, Lapierre $\mathrm{H}$ et al. Results of the minimally invasive coronary artery bypass grafting angiographic patency study. The Journal of thoracic and cardiovascular surgery 2014;147:203-209.

41. Gulielmos V, Brandt M, Dill H-M et al. Coronary artery bypass grafting via median sternotomy or lateral minithoracotomy. European Journal of Cardio-Thoracic Surgery 1999;16:S48-S52.

42. van Gulik L, Janssen LI, Ahlers SJ et al. Risk factors for chronic thoracic pain after cardiac surgery via sternotomy. European Journal of Cardio-thoracic Surgery 2011;40:1309-1313.

43. Lahtinen P, Kokki H, Hynynen M. Pain after Cardiac SurgeryA Prospective Cohort Study of 1-Year Incidence and Intensity. Anesthesiology: The Journal of the American Society of Anesthesiologists 2006;105:794800.

44. Meyerson J, Thelin S, Gordh T, Karlsten R. The incidence of chronic post-sternotomy pain after cardiac surgery-a prospective study. Acta Anaesthesiologica Scandinavica 2001;45:940-944.

45. Bayman EO, Brennan TJ. Incidence and severity of chronic pain at 3 and 6 months after thoracotomy: meta-analysis. The Journal of Pain 2014;15:887-897. 
The Unrecognized Patient and Economic Burdens of Post Coronary Artery Bypass Grafting Surgery Morbidities: Could Contemporary Medical Therapy Play a Bigger Role?

46. Peng Z, Li H, Zhang C, Qian X, Feng Z, Zhu S. A retrospective study of chronic post-surgical pain following thoracic surgery: prevalence, risk factors, incidence of neuropathic component, and impact on qualify of life. PLoS One 2014;9:e90014.

47. Guimarães-Pereira L, Farinha F, Azevedo L, Abelha F, Castro-Lopes J. Persistent postoperative pain after cardiac surgery: incidence, characterization, associated factors and its impact in quality of life. European Journal of Pain 2016;20:1433-1442.

48. Theunissen M, Peters ML, Bruce J, Gramke H-F, Marcus MA. Preoperative anxiety and catastrophizing: a systematic review and meta-analysis of the association with chronic postsurgical pain. The Clinical journal of pain 2012;28:819-841.

49. Pagé MG, Watt-Watson J, Choinière $M$. Do depression and anxiety profiles over time predict persistent post-surgical pain? A study in cardiac surgery patients. European Journal of Pain 2017;21:965-976.

50. Tully PJ, Baumeister H, Bennetts JS, Rice GD, Baker RA. Depression screening after cardiac surgery: a six month longitudinal follow up for cardiac events, hospital readmissions, quality of life and mental health. International journal of cardiology 2016;206:44-50.

51. Blumenthal JA, Lett HS, Babyak MA et al. Depression as a risk factor for mortality after coronary artery bypass surgery. Lancet (London, England) 2003;362:604-9.

52. Steptoe A, Poole L, Ronaldson A, Kidd T, Leigh E, Jahangiri M. Depression 1 year after CABG is predicted by acute inflammatory responses. Journal of the American College of Cardiology 2015;65:1710-1711.

53. Poole L, Kidd T, Ronaldson A, Leigh E, Jahangiri M, Steptoe A. Depression 12-months after coronary artery bypass graft is predicted by cortisol slope over the day. Psychoneuroendocrinology 2016;71:155-158.

54. Jongman RM, Zijlstra JG, Kok WF et al. Off-pump CABG surgery reduces systemic inflammation compared with on-pump surgery but does not change systemic endothelial responses: a prospective randomized study. Shock 2014;42:121-128.

55. Ghoneim MM, O'Hara MW. Depression and postoperative complications: an overview. BMC surgery 2016;16:5.

56. Tully PJ, Winefield HR, Baker RA et al. Depression, anxiety and major adverse cardiovascular and cerebrovascular events in patients following coronary artery bypass graft surgery: a five year longitudinal cohort study. BioPsychoSocial medicine 2015;9:14.

57. Nicholson A, Kuper H, Hemingway H. Depression as an aetiologic and prognostic factor in coronary heart disease: a meta-analysis of 6362 events among 146538 participants in 54 observational studies. European heart journal 2006;27:2763-2774.

58. McKenzie LH, Simpson J, Stewart M. A systematic review of pre-operative predictors of post-operative depression and anxiety in individuals who have undergone coronary artery bypass graft surgery. Psychology, health \& medicine 2010;15:74-93.

59. Zakkar M, Ascione R, James A, Angelini G, Suleiman M. Inflammation, oxidative stress and postoperative atrial fibrillation in cardiac surgery. Pharmacology \& therapeutics 2015;154:13-20.

60. Jacob KA, Nathoe HM, Dieleman JM, Osch D, Kluin J, Dijk D. Inflammation in new-onset atrial fibrillation after cardiac surgery: a systematic review. European journal of clinical investigation 2014;44:402-428.

61. Nah HW, Lee JW, Chung $\mathrm{CH}$ et al. New brain infarcts on magnetic resonance imaging after coronary artery bypass graft surgery: lesion patterns, mechanism, and predictors. Annals of neurology 2014;76:347-355. 
The Unrecognized Patient and Economic Burdens of Post Coronary Artery Bypass Grafting Surgery Morbidities: Could Contemporary Medical Therapy Play a Bigger Role?

62. Reents W, Hilker M, Börgermann J et al. Acute kidney injury after on-pump or off-pump coronary artery bypass grafting in elderly patients. The Annals of thoracic surgery 2014;98:9-15.

63. Chokkalingam M, Saradha S, Navitha A, Nayar PG. Incidence and clinical profile of patients with frozen shoulder after cardiac surgery. Journal of Clinical and Preventive Cardiology 2017;6:142.

64. Goto T, Maekawa K. Cerebral dysfunction after coronary artery bypass surgery. Journal of anesthesia 2014;28:242-248.

65. Warren J, Mehran R, Baber U et al. Incidence and impact of acute kidney injury in patients with acute coronary syndromes treated with coronary artery bypass grafting: Insights from the Harmonizing Outcomes With Revascularization and Stents in Acute Myocardial Infarction (HORIZONS-AMI) and Acute Catheterization and Urgent Intervention Triage Strategy (ACUITY) trials. American heart journal 2016;171:40-47.

66. Zarbock A, Schmidt C, Van Aken $\mathrm{H}$ et al. Effect of remote ischemic preconditioning on kidney injury among high-risk patients undergoing cardiac surgery: a randomized clinical trial. Jama 2015;313:2133-2141.

67. Alraies MC, Al Jaroudi W, Shabrang C, Yarmohammadi H, Klein AL, Tamarappoo BK. Clinical features associated with adverse events in patients with post-pericardiotomy syndrome following cardiac surgery. American Journal of Cardiology 2014;114:1426-1430.

68. Al-Shaar L, Schwann TA, Kabour A, Habib RH. Increased late mortality after coronary artery bypass surgery complicated by isolated new-onset atrial fibrillation: A comprehensive propensity-matched analysis. The Journal of thoracic and cardiovascular surgery 2014;148:1860-1868. e2.

69. El-Chami MF, Kilgo P, Thourani $\mathrm{V}$ et al. New-onset atrial fibrillation predicts long-term mortality after coronary artery bypass graft. Journal of the American College of Cardiology 2010;55:1370-1376.

70. Haddad TM, Parekh J, Jhand A et al. OUTCOMES OF POST-OPERATIVE ATRIAL FIBRILLATION AFTER CORONARY ARTERY BYPASS GRAFT SURGERY: A META-ANALYSIS. Journal of the American College of Cardiology 2018;71:A144.

71. Thrall G, Lane D, Carroll D, Lip GY. Quality of life in patients with atrial fibrillation: a systematic review. The American journal of medicine 2006;119:448. e1-448. e19.

72. Gulack BC, Kirkwood KA, Shi W et al. Secondary surgical-site infection after coronary artery bypass grafting: A multi-institutional prospective cohort study. The Journal of thoracic and cardiovascular surgery 2017.

73. Likosky DS, Paone G, Zhang M et al. Red blood cell transfusions impact pneumonia rates after coronary artery bypass grafting. The Annals of thoracic surgery 2015;100:794-801.

74. Brescia AA, Rankin JS, Cyr DD et al. Determinants of Variation in Pneumonia Rates After Coronary Artery Bypass Grafting. The Annals of thoracic surgery 2017.

75. Lemaignen A, Birgand G, Ghodhbane $W$ et al. Sternal wound infection after cardiac surgery: incidence and risk factors according to clinical presentation. Clinical Microbiology and Infection 2015;21:674. e11-674. e18.

76. Crabtree TD, Codd JE, Fraser VJ, Bailey MS, Olsen MA, Damiano Jr RJ. Multivariate analysis of risk factors for deep and superficial sternal infection after coronary artery bypass grafting at a tertiary care medical center. Seminars in thoracic and cardiovascular surgery: Elsevier, 2004:53-61.

77. Strobel RJ, Liang Q, Zhang $\mathrm{M}$ et al. A preoperative risk model for postoperative pneumonia after coronary artery bypass grafting. The Annals of thoracic surgery 2016;102:1213-1219. 
The Unrecognized Patient and Economic Burdens of Post Coronary Artery Bypass Grafting Surgery Morbidities: Could Contemporary Medical Therapy Play a Bigger Role?

78. Athanasiou T, Aziz 0, Skapinakis $\mathrm{P}$ et al. Leg wound infection after coronary artery bypass grafting: a meta-analysis comparing minimally invasive versus conventional vein harvesting. The Annals of thoracic surgery 2003;76:2141-2146.

79. Poeran J, Mazumdar M, Rasul R et al. Antibiotic prophylaxis and risk of Clostridium difficile infection after coronary artery bypass graft surgery. The Journal of thoracic and cardiovascular surgery 2016;151:589597. e2.

80. Tan N, Sampath R, Abu Saleh OM et al. Disseminated Mycobacterium chimaera infection after cardiothoracic surgery. Open forum infectious diseases: Oxford University Press, 2016.

81. Mao Z, Zhong X, Yin J, Zhao Z, Hu X, Hackett ML. Predictors associated with stroke after coronary artery bypass grafting: a systematic review. Journal of the neurological sciences 2015;357:1-7.

82. Masabni K, Raza S, Blackstone EH, Gornik HL, Sabik JF. Does preoperative carotid stenosis screening reduce perioperative stroke in patients undergoing coronary artery bypass grafting? The Journal of thoracic and cardiovascular surgery 2015;149:1253-1260.

83. Athappan G, Chacko P, Patvardhan E, Gajulapalli RD, Tuzcu EM, Kapadia SR. Late stroke: comparison of percutaneous coronary intervention versus coronary artery bypass grafting in patients with multivessel disease and unprotected left main disease: a meta-analysis and review of literature. Stroke 2014;45:185193.

84. Morice M-C, Serruys PW, Kappetein AP et al. Five-year outcomes in patients with left main disease treated with either percutaneous coronary intervention or coronary artery bypass grafting in the SYNTAX trial. Circulation 2014:CIRCULATIONAHA. 113.006689.

85. Mohr FW, Morice M-C, Kappetein AP et al. Coronary artery bypass graft surgery versus percutaneous coronary intervention in patients with three-vessel disease and left main coronary disease: 5-year followup of the randomised, clinical SYNTAX trial. The lancet 2013;381:629-638.

86. Misfeld M, Brereton RJL, Sweetman EA, Doig GS. Neurologic complications after off-pump coronary artery bypass grafting with and without aortic manipulation: meta-analysis of 11,398 cases from 8 studies. The Journal of thoracic and cardiovascular surgery 2011;142:e11-e17.

87. Kara I, Erkin A, Saclı $\mathrm{H}$ et al. The effects of Near-Infrared spectroscopy on the neurocognitive functions in the patients undergoing coronary artery bypass grafting with asymptomatic carotid artery disease: a randomized prospective study. Annals of Thoracic and Cardiovascular Surgery 2015;21:544-550.

88. Colak Z, Borojevic M, Bogovic A, Ivancan V, Biocina B, Majeric-Kogler V. Influence of intraoperative cerebral oximetry monitoring on neurocognitive function after coronary artery bypass surgery: a randomized, prospective study. European Journal of Cardio-Thoracic Surgery 2014;47:447-454.

89. Lingehall HC, Smulter NS, Lindahl E et al. Preoperative cognitive performance and postoperative delirium are independently associated with future dementia in older people who have undergone cardiac surgery: A longitudinal cohort study. Critical care medicine 2017;45:1295.

90. Evered LA, Silbert BS, Scott DA, Maruff P, Ames D. Prevalence of dementia 7.5 years after coronary artery bypass graft surgery. Anesthesiology: The Journal of the American Society of Anesthesiologists 2016;125:62-71.

91. García-Delgado M, Navarrete-Sánchez I, Colmenero M. Preventing and managing perioperative pulmonary complications following cardiac surgery. Current Opinion in Anesthesiology 2014;27:146-152. 
The Unrecognized Patient and Economic Burdens of Post Coronary Artery Bypass Grafting Surgery Morbidities: Could Contemporary Medical Therapy Play a Bigger Role?

92. Wynne $R$, Botti M. Postoperative pulmonary dysfunction in adults after cardiac surgery with cardiopulmonary bypass: clinical significance and implications for practice. American journal of critical care 2004;13:384-393.

93. Morsch KT, Leguisamo CP, Camargo MD et al. Ventilatory profile of patients undergoing CABG surgery. Brazilian Journal of Cardiovascular Surgery 2009;24:180-187.

94. Westerdahl E, Lindmark B, Bryngelsson I, Tenling A. Pulmonary function 4 months after coronary artery bypass graft surgery. Respiratory medicine 2003;97:317-322.

95. Pasquina P, Walder B. Prophylactic respiratory physiotherapy after cardiac surgery: systematic review. Bmj 2003;327:1379.

96. Sajja LR, Mannam G, Chakravarthi RM etal. Coronaryartery bypass grafting with or without cardiopulmonary bypass in patients with preoperative non-dialysis dependent renal insufficiency: A randomized study. The Journal of Thoracic and Cardiovascular Surgery 2007;133:378-388. e3.

97. Liotta M, Olsson D, Sartipy U, Holzmann MJ. Minimal changes in postoperative creatinine values and early and late mortality and cardiovascular events after coronary artery bypass grafting. American Journal of Cardiology 2014;113:70-75.

98. Rydén L, Sartipy U, Evans M, Holzmann MJ. Acute kidney injury after coronary artery bypass grafting and long-term risk of end-stage renal disease. Circulation 2014:CIRCULATIONAHA. 114.010622.

99. Cooper WA, O'brien SM, Thourani VH et al. Impact of renal dysfunction on outcomes of coronary artery bypass surgery: results from the Society of Thoracic Surgeons National Adult Cardiac Database. Circulation 2006;113:1063-1070.

100. Nigwekar SU, Kandula P, Hix JK, Thakar CV. Off-pump coronary artery bypass surgery and acute kidney injury: a meta-analysis of randomized and observational studies. American journal of kidney diseases 2009;54:413-423.

101. Leffell MS, Kim D, Vega RM et al. Red blood cell transfusions and the risk of allosensitization in patients awaiting primary kidney transplantation. Transplantation 2014;97:525-533.

102. Fihn SD, Gardin JM, Abrams J et al. 2012 ACCF/AHA/ACP/AATS/PCNA/SCAI/STS guideline for the diagnosis and management of patients with stable ischemic heart disease: a report of the American College of Cardiology Foundation/American Heart Association task force on practice guidelines, and the American College of Physicians, American Association for Thoracic Surgery, Preventive Cardiovascular Nurses Association, Society for Cardiovascular Angiography and Interventions, and Society of Thoracic Surgeons. Journal of the American College of Cardiology 2012;60:e44-e164.

Citation: Abolfazl Dohaei, M.D., Wayne L. Miller, M.D., Ph.D., "The Unrecognized Patient and Economic Burdens of Post Coronary Artery Bypass Grafting Surgery Morbidities: Could Contemporary Medical Therapy Play a Bigger Role?". American Research Journal of Cardiovascular Diseases, 3(1); pp: 1-13.

Copyright (c) 2019 Abolfazl Dohaei, M.D., Wayne L. Miller, M.D., Ph.D., This is an open access article distributed under the Creative Commons Attribution License, which permits unrestricted use, distribution, and reproduction in any medium, provided the original work is properly cited. 